\title{
“Eu Não Tenho Direito de Me Desanimar”: Sofrimento no Trabalho de Executivos
}

\author{
Fernanda Lottermann* (D, Carmem Regina Giongo (1), \\ \& Lisiane Machado de Oliveira-Menegotto (1) \\ Universidade Feevale, Novo Hamburgo, RS, Brasil
}

\begin{abstract}
RESUMO - Este estudo analisa os reflexos que as vivências de trabalho exercem sobre a saúde mental dos executivos das indústrias alimentícias do Vale do Caí, Rio Grande do Sul. Com delineamento qualitativo, a pesquisa contou com oito entrevistados. Utilizaram-se entrevistas focalizadas e questionários. Os dados foram examinados por meio da análise de conteúdo proposta por Laville e Dionne. O medo do desligamento e a necessidade de abdicarem da própria subjetividade em prol da empresa são fatores de sofrimento. A organização do trabalho é negligente com cuidados à saúde mental e promove modos mecanicistas de ser, agravando os riscos à integridade dos trabalhadores. A psicologia promove reflexões e possibilita a ressignificação do sofrimento gerado pelo trabalho.
\end{abstract}

PALAVRAS-CHAVE: psicodinâmica do trabalho, sofrimento, executivos

\section{“I Don't Have the Right to Despond Myself": The Executive's Work Suffering}

\begin{abstract}
This study analyzes the repercussions of the work experience on the mental health of the executives of the food industry in the region of Vale do Caí, Rio Grande do Sul state, Brazil. With the qualitative design, the survey counted on eight interviewees. We used focused interviews and questionnaires. The data were assessed by the content analysis proposed by Laville and Dionne. The fear of dismissal and the need to abdicate one's subjectivity in favor of the company are factors for suffering. The organization of work is negligent with mental health care and promotes mechanistic ways of being, aggravating the risks to the integrity of workers. Psychology promotes reflections and enables the resignification of the suffering generated by work.
\end{abstract}

KEYWORDS: work psychology, psychodynamics, suffering, executives

As características do trabalho vêm se modificando ao longo do tempo por influência de diferentes aspectos sociais, econômicos e culturais. De acordo com Merlo e Lapis (2007), a consolidação do capitalismo sofreu influências de inúmeros ciclos de crescimento e crises, sendo marcada por importantes mudanças nos modos de organizar o trabalho e a produção. Assim, a partir da última parte do século $\mathrm{XX}$, a competitividade existente no mercado exigiu uma reformulação nos processos produtivos que passaram a priorizar uma maior produtividade ao mais baixo custo.

Atualmente, o mercado de trabalho continua se modificando, mais ainda sob o imperativo do aumento da lucratividade e da necessidade competitiva imposta pela globalização da produção (Casttells, 1999; Laranjeira, 2000), principalmente por meio do baixíssimo custo, fator que influencia diretamente as relações de trabalho. Esse contingente de mudanças nas estruturações produtivas e nas formas de relacionar-se com o trabalho desenvolveu, ao longo dos anos, novas maneiras de vinculação e relações trabalhistas. De acordo com Antunes e Alves (2004), os vínculos trabalhistas se tornaram precários a partir dessas modificações. Pensando que a atual situação do mercado de trabalho transformou as relações e a subjetividade presente na atividade laboral em "coisas" a serem consumidas, compreende-se o aumento dos sintomas e das doenças que afastam o trabalhador de suas tarefas.

\footnotetext{
* E-mail: fernandalottermann@hotmail.com

- Submetido: 04/04/2017; Aceito: 07/02/2018.
} 
Além de propiciar aos sujeitos a sobrevivência, a integração social e o reconhecimento, o trabalho é considerado um mediador entre a ordem singular e a ordem coletiva que possibilita a vinculação a diferentes grupos, a gratificação, o equilíbrio entre saúde e doença, a realização pessoal e a historização do sujeito (Dejours et al., 2010; Lancman \& Ghirardi, 2002). Os fatores construtivos do trabalho citados até o momento são resultados de uma forma de trabalho nomeada pela psicodinâmica como trabalho equilibrante. No entanto, cabe ressaltar que nenhuma atividade ou organização está livre de situações danosas, que podem ser fonte de adoecimento caso os trabalhadores não encontrem formas de aliviar a carga psíquica gerada diariamente. O chamado trabalho fatigante torna-se, assim, um perigo para a saúde física e mental do trabalhador (Dejours et al., 2010).

Sendo o sofrimento inerente ao ambiente de trabalho, entende-se que, quanto mais rígido e menos oportunidades ele oferece ao trabalhador de investir na inteligência prática, maior se torna a possibilidade do trabalho se tornar patogênico. Nesse sentido, quanto maior for o distanciamento entre as práticas prescritas do trabalho e a realidade, maior também será o sofrimento. Segundo Vasconcelos e Faria (2008), o sofrimento que não é compartilhado pelos sujeitos "tem maior probabilidade de se tornar uma doença individual, com uma solução também individual: $\mathrm{o}$ afastamento, o desligamento ou o medicamento como possibilidade de se manter trabalhando" (p. 462). Ao contrário do individualismo, as ações coletivas entre trabalhadores são consideradas estratégias de enfretamento frente às características patologizantes da organização do trabalho. Sobre a importância do coletivo de trabalho e das práticas que estes desenvolvem em seus núcleos, sabe-se que, além de aumentarem a tolerância frente ao sofrimento, também protegem o trabalhador dos riscos dos quais não conseguem se desvencilhar.

Nesse sentido, torna-se relevante a ressalva de Martins e Mendes (2012) de que o espaço público de reflexão dentro das cenas de trabalho, onde os coletivos possam se reunir para discutir, interagir, contar histórias, expressar e refletir sobre o sofrimento e buscarem novos significados para os acontecimentos diários, são fundamentais para reduzir os riscos do trabalho. Um aspecto de fundamental importância para a compreensão e busca da saúde mental do trabalhador é a autonomia, que abre espaço para que o trabalhador coloque sua subjetividade no trabalho (Mendes \& Facas, 2010).

As consequências do trabalho são relatadas por meio de diversas pesquisas e estudos publicados em periódicos científicos. Quando se trata de pesquisas desenvolvidas com os trabalhadores da indústria, em especial os executivos, o número de estudos é menor. Em uma pesquisa nas bases Periódicos Capes e BVS-Psi, fazendo uso dos termos "saúde" e "executivos", localizaram-se quatro artigos (Couto, 1987; Mota et al., 2008; Oltramari et al., 2011; Tanure et al., 2014), sendo três deles relacionados ao estresse.
Diante desses resultados, pode-se concluir que são escassas as investigações que possuem como foco a temática da saúde mental dos trabalhadores que atuam no segmento industrial, especialmente dos profissionais que ocupam cargos de gestão, portanto, um campo fértil para a realização de estudos. Além desta escassez, se torna relevante considerar a abrangência das decisões tomadas diariamente por esses profissionais. As decisões dos executivos exercem influência direta no futuro das organizações e, consequentemente, nos investimentos feitos por estas em prol da saúde mental dos trabalhadores.

\section{As Indústrias do Setor de Alimentos e o Trabalho dos Executivos}

De acordo com o Instituto Brasileiro de Geografia e Estatística (IBGE), o setor se caracteriza principalmente pelo processo de transformação de insumos agrícolas, pecuários e de pesca em alimentos para uso humano e animal (IBGE como citado em Cardoso, 2012). No Vale do Caí, estado do Rio Grande do Sul (RS), região objeto deste estudo, apesar de o número de demissões, o setor industrial de maior expressividade continua sendo o de transformação de alimentos. A fabricação de alimentos detém o maior número de empregados, em sua maioria distribuídos nas cidades de São Sebastião do Caí e Montenegro (Bertê et al., 2016).

Sendo a produção de alimentos um dos setores mais produtivos, não apenas na região citada, mas em todo o país, sabe-se que a competição se acirra. As empresas desse setor competem entre si de diferentes formas, seja nos preços, seja na qualidade dos produtos. Atualmente, as indústrias de alimentos têm como característica processos produtivos mecanizados, padronizados, que exigem esforço contínuo do trabalhador (Sato \& Lacaz, 2000). Entende-se que as características desse modelo de organização de trabalho incidem sobre todos os trabalhadores inseridos em determinada realidade, sem distinção de raça, crença, formação ou posição hierárquica. Muitos deles acumulam tarefas e funções e se comprometem com metas e objetivos cada vez maiores, na tentativa de superar o atual cenário econômico instalado em nosso país e, assim, manterem-se empregados.

O nível de cobrança, o excesso de carga horária de trabalho, as pressões, a falta de perspectiva de futuro, o clima social instável e as pressões por metas, entre outros fatores, geram nos executivos uma sensação de malestar (Maffia \& Pereira, 2013). As constantes tensões e preocupações experenciadas pelos executivos os colocam em estado de alerta diário, impossibilitando os momentos de relaxamento e de equilíbrio entre o tempo de trabalho e o de não-trabalho (Couto, 1987). De acordo com Sarriera e Silva (2003), o papel dos executivos dentro das organizações é inevitavelmente exposto a diversas situações conflituosas devido a uma contradição histórica: de um lado, a defesa dos interesses da empresa; de outro, os interesses dos 
trabalhadores. Diante disso, o presente estudo tem o objetivo de analisar as vivências de prazer e sofrimento no trabalho dos executivos das indústrias do setor alimentício da região do Vale do Caí e os reflexos destas vivências na saúde mental do trabalhador, buscando contribuir para o aprofundamento das discussões que abordam tal temática.

\section{MÉTODO}

O presente estudo foi orientado teoricamente pela Psicodinâmica do Trabalho (Dejours, 2004) e possui delineamento exploratório de metodologia qualitativa. Como ferramenta de coleta, utilizou-se uma entrevista semiestruturada baseada nos pressupostos da Psicodinâmica do trabalho, abordando questões como as vivências de sofrimento e de prazer e os efeitos sobre o corpo. Além da entrevista, fez-se uso de um questionário composto por questões como sexo, idade, escolaridade, estado civil, quantidade de filhos, tempo de atuação no cargo, média salarial, afastamentos e/ou adoecimentos relacionados ao trabalho. As informações levantadas por meio do questionário contribuíram para a descrição dos participantes da pesquisa.

Contou-se com a participação de oito executivos. Para a pesquisa, consideraram-se os profissionais que atuavam em empresas do setor alimentício do Vale do Caí (cortes de aves, enlatados, congelados/resfriados), não sendo estes necessariamente moradores da região. Os critérios de inclusão exigiam que os profissionais estivessem atuando no mínimo há 2 anos na mesma empresa, com idade superior a 18 anos, independentemente do nível de escolaridade, com função registrada e formalizada de gerente, diretor ou presidente. A população $(n=8)$ de executivos entrevistados se dividiu igualmente entre homens e mulheres, com idade média de 35,1 anos ( $\mathrm{DP}=5,010)$. Quanto à escolaridade, um executivo ainda estava em processo de graduação, outros dois eram graduados e os demais eram pós-graduados. Quanto ao nível hierárquico, um era diretor e os demais atuavam como gerentes.

Ao dar início ao processo de coleta de dados para a pesquisa, se fez necessário um mapeamento das indústrias do setor alimentício da região. Após a seleção dos executivos e a definição oficial da ferramenta, as entrevistas foram agendadas. Como não foi possível compor a amostra de oito executivos apenas com os procedimentos citados, fezse uso do método snowball (Biernacki \& Waldorf, 1981), caracterizado pela indicação por parte dos entrevistados de outros possíveis participantes. Cada entrevista teve duração de, no máximo, 2 horas, tendo o seu áudio gravado. Todos os participantes assinaram o Termo de Consentimento Livre e Esclarecido (TCLE). O projeto em questão foi submetido ao Comitê de Ética em Pesquisa da Universidade Feevale e aprovado sob o protocolo número 1.656.212.

As transcrições foram analisadas de acordo com a metodologia da análise de conteúdo proposta por Laville e Dionne (1999). Do ponto de vista operacional, o pesquisador deve buscar preparar o material coletado para posterior exploração e decisão sobre a escolha da melhor maneira para decompô-lo (Laville \& Dionne, 1999). A fase seguinte se caracteriza pelo recorte do conteúdo, onde o pesquisador deverá desmembrar o material coletado. Dessa forma, "os elementos assim recortados vão constituir as unidades de análise", que devem ser completos em si mesmos, compostos de um significado e de uma ideia própria. Em seguida, identificam-se as categorias analíticas, nas quais os recortes efetuados anteriormente serão organizados por critério de parentesco de sentido (Laville \& Dionne, 1999, p. 216). Neste estudo, foi utilizado o modelo de categorização misto, definido como padrão em pesquisas que determinam as categorias utilizando temas definidos a priori e a posteriori (Laville \& Dionne, 1999). Cabe destacar que, ao longo da análise de dados, fez-se uso de nomes fictícios, buscando preservar a identidade dos participantes.

\section{RESULTADOS}

A apresentação do material se dividirá em quatro categorias distintas: a) A Organização do Trabalho; b) $\mathrm{O}$ Medo do Desligamento; c) As Relações Socioprofissionais: a Ausência do Coletivo entre Executivos; d) O Relacionamento com as Equipes e os Efeitos sobre o Corpo.

\section{Organização do Trabalho}

Cada categoria de profissionais tem, em seu entorno, um modelo próprio de organização de trabalho e este, por sua vez, favorece ou não a saúde mental dos trabalhadores (Mendes, 1995). No contexto desta investigação, percebeu-se que o grupo de entrevistados não vivencia uma organização de trabalho única, mas, apesar de serem distintas quanto ao produto final e quanto aos procedimentos técnicos, se organizam de maneira semelhante para cumprir as exigências impostas pelos órgãos regulamentadores. Dessa forma, percebeu-se que as indústrias, além de estabelecerem vínculos de trabalho formais com seus colaboradores, têm seu funcionamento estabelecido ao longo de 24 horas, divididas em 3 turnos distintos. Além disso, destaca-se a tentativa das organizações industriais de padronizar o comportamento e as ações dos trabalhadores por meio de prescrições e de normas de qualidade. 
Outro elemento que compõe a organização de trabalho nas indústrias alimentícias, em especial, as atividades dos profissionais executivos, é a dedicação exclusiva ao cargo. De maneira geral, os oito entrevistados relataram trabalhar mais do que 44 horas semanais. Identificou-se, ainda, que o excesso de cobrança frente aos resultados, a aderência às normas e burocracias (que tornam o trabalho repetitivo e monótono), a gestão de pessoas e de produção e a necessidade de se manterem neutros frente aos próprios sentimentos em relação ao trabalho compõem o cenário de trabalho em que esses profissionais se inserem.

Além do acúmulo de funções, outra característica predominante na organização do trabalho dos executivos da indústria do setor de alimentos é o rigor frente aos processos de controle de qualidade. Os executivos são responsáveis por tornar conhecidas, entre os trabalhadores, todas as normas de controle de qualidade, além de fazê-las serem cumpridas da maneira exigida pelos órgãos reguladores. Nesse contexto, pode-se identificar na fala a seguir uma preocupação quanto ao excesso de cobrança relacionada ao tema da qualidade total: "Isso é um pouquinho estressante, porque uma norma dessas tem mais de 300 requisitos. Então, são detalhes muito específicos e acabam exigindo um certo grau de estresse, porque tu precisa fazer com que se cumpram". (Maurício, comunicação pessoal, 22 de agosto, 2016).

Nas entrevistas, identificaram-se momentos em que o processo rigoroso de controle de qualidade é percebido com tanta naturalidade que o fato de gerar conflitos não causa nenhum estranhamento. Esse aspecto pode ser observado na fala abaixo:

É inevitável falar hoje de produção e qualidade sem ter alguns momentos em que essas duas coisas se conflitam. E isso gera um desgaste. E, normalmente, as coisas acontecem ao natural. $\mathrm{E}$, às vezes, gera conflito entre a minha equipe e a equipe da produção [...] Mas isso é muito comum entre os setores de qualidade e produção, acontece em todos os lugares. (Augusto, comunicação pessoal, 11 de agosto, 2016).

Os executivos envolvidos com os sistemas de qualidade se referem aos períodos de inspeção como uma fonte de mudanças na rotina de trabalho e em seus comportamentos. Um exemplo disso pode ser evidenciado no recorte a seguir: "Eu acho que, em épocas de auditorias, que são épocas mais tensas, eu tenho diferença de comportamento. Não consigo tirar o trabalho da cabeça. É mais difícil de separar". (Augusto, comunicação pessoal, 11 de agosto, 2016).

Frente a esse contexto, grande parte dos executivos expôs que as formas de organização do trabalho exigem cargas horárias excessivas. Por vezes, essa característica demanda que eles abram mão de cuidados com a própria saúde ou com a vida pessoal, como pode ser percebido na próxima fala:

Não. Não tem como sair ou me afastar. Vou mostrar o atestado pra quem? Esses tempos teve um médico que me disse: "Leva um atestado pra ti ficar uns dois ou três dias em casa”. Olhei pra ele e disse: "Olha doutor, amanhã eu levanto às 5 horas pra sair pra trabalhar. Me dá um remédio que tá ótimo". (Nair, comunicação pessoal, 27 de agosto, 2016).

Além dos entrevistados abrirem mão dos cuidados com a própria saúde, deixam de lado atividades sociais em prol das rotinas profissionais. Como agravante, os executivos relatam não terem a oportunidade de gozar suas férias no prazo determinado por lei. Um dos entrevistados relatou que, quando for possível cumprir os seus 30 dias de férias rigorosamente, ele ficará preocupado, já que, quando um funcionário se afasta, a empresa tende a posicionar outro trabalhador no seu lugar.

Férias eu tiro, sim. Parcelado, mas tiro. Tiro no máximo 20 (dias), divididos em duas (vezes) de 10 (dias). Trinta dias é impossível; o dia que eu conseguir 30, eu vou começar a me preocupar (risadas). Quando eu entrei, claro que, legalmente, isso não pode, mas eu não tirava férias. (Augusto, comunicação pessoal, 11 de agosto, 2016).

\section{O Medo do Desligamento}

Durante a coleta, percebeu-se entre o coletivo entrevistado que o medo do desligamento permeia as vivências de trabalho de todos os trabalhadores. Um exemplo que pode ser citado é o de Leonora, gerente de recursos humanos:

As demissões foram em maio e junho, foram os meses mais difíceis. [...]mas ficava com aquele fantasma das demissões. Foram um total de 800 demissões em todo o grupo [...] $\mathrm{Eu}$ chorava muito quando precisei fazer, parecia que a responsabilidade era minha. (Leonora, comunicação pessoal, 08 de agosto, 2016).

Outra executiva entrevistada relata que o sentimento que se destaca ao ter que lidar com o desligamento dos demais trabalhadores é o de frustação. Conforme Rafaela, "quando tu tem que desligar uma pessoa e largar ela sem ter outra coisa, dá uma frustração, porque tu investiu teu tempo, quer dizer, teu tempo como tempo da empresa, mas que também é teu tempo, não tem como dissociar" (Rafaela, comunicação pessoal, 01 de agosto, 2016).

Assim, vale ressaltar que, da mesma forma que os demais trabalhadores, os profissionais que ocupam cargos de gestão também sofrem diante dos fantasmas do desemprego. De acordo com os entrevistados, atualmente, nada é garantia de estabilidade profissional. Os participantes da pesquisa atestaram que, independentemente do tempo de empresa ou de outras variáveis, qualquer um poderia ser, sem maiores explicações, destituído de seus cargos ou funções. Fabrício, gerente de logística, explica essa situação: "Mas eles trocam de gente como trocam de roupa. E é ruim, é muito ruim. Não sei se é da empresa, mas não deveria ser [...]É ruim, porque 
as pessoas se sentem instáveis" (Fabrício, comunicação pessoal, 19 de agosto, 2016).

A insegurança aparece relacionada, predominantemente, à atual situação econômica do mercado, bem como ao temor de não atingir as metas estipuladas e/ou não corresponder às expectativas da organização, como demonstrado no recorte da fala de Rafaela: "porque, se amanhã ou depois for ruim pra eles ou ruim pra mim, esse relacionamento (vínculo de trabalho) vai terminar" (Rafaela, comunicação pessoal, 01 de agosto, 2016). Já Cíntia relata que sua insegurança é reforçada pela organização do trabalho como uma forma de estimular a produção: "Então, é bem isso, não tem ninguém seguro. Então tu tem que também conseguir rebolar, sair da tua zona de conforto. Querendo ou não, tu é funcionário e tu pode acabar entrando na lista de desligamentos" (Cíntia, comunicação pessoal, 06 de setembro, 2016).

\section{As Relações Socioprofissionais: A Ausência do Coletivo Entre Executivos e o Relacionamento com as Equipes}

Outro aspecto bastante marcante nas falas dos entrevistados foi a ausência do coletivo de trabalho. Percebeu-se uma tendência das organizações pesquisadas em reunirem seus executivos apenas quando algo de muito ruim está acontecendo. É nesse contexto que um dos relatos demonstra que, por falta de um coletivo com quem possa falar sobre o trabalho, o profissional acaba guardando esse tipo de informação consigo mesmo:

Por isso que essa conversa de agora é tão produtiva. É o momento que eu tenho pra falar e pensar esse tipo de coisa, [...]Se não fica tudo guardado comigo... Porque, pra mim, era o tempo de falar e pensar o trabalho e não precisar fazer isso fora, ou em casa. (Fabrício, comunicação pessoal, 19 de agosto, 2016).

Se por um lado as relações entre os executivos são escassas, por outro, os próprios profissionais consideram que essa não é uma possibilidade para as equipes que comandam. Entre os entrevistados, surgiu certa preocupação frente às relações estabelecidas com os colaboradores, sob a justificativa de que esse tema pode exercer interferências nos resultados do trabalho. Além disso, por ocuparem um cargo de gestão, os executivos sentem-se na obrigação de não demostrarem seus descontentamentos e sofrimentos em relação ao trabalho, por acreditarem na influência negativa que o ato poderia gerar na equipe. O relato de Rafaela auxilia na exposição dessa temática:

Não... Eu não tenho direito de me desanimar, se eu me desanimar, eles se desanimam mais ainda [...] apesar de eu achar que ele tem toda a razão, eu sempre tento estimular a calma. Se eu chegar bem, eles também ficam, se eu chegar meio mais ou menos, eles logo percebem... É uma convivência de muito tempo. (Rafaela, comunicação pessoal, 01 de agosto, 2016).
Percebeu-se o empenho da executiva em manter a equipe animada e motivada. No entanto, nota-se que tal tendência pode ser gerada a partir de uma exigência da própria organização do trabalho, que acaba anulando a subjetividade do próprio executivo. Como exemplo, cita-se a fala de Fabrício ao (comunicação pessoal, 19 de agosto, 2016) afirmar que "é uma coisa que a gente tem que fazer, uma lavagem cerebral nos caras e o cara que não se adapta a isso, não serve. Em uma empresa, infelizmente, é assim”.

$\mathrm{O}$ entrevistado, ao se referir às relações que ele estabelece com sua equipe, demonstra a utilização de um discurso institucionalizado na tentativa de interagir com os demais trabalhadores e de alcançar as metas organizacionais. Nesse sentido, ressalta-se a fala de Maurício, que utilizou o termo "político" ao se referir às formas que ele utiliza para relacionar-se interpessoalmente com sua equipe e, assim, atingir as metas da organização: "Quando eu tô bastante estressado, tenho uma mudança significativa de humor e isso acaba afetando [...]Acho que tudo é uma política. Acho que a gente tem que tentar fazer um jogo adequado pra que tudo dê certo" (Maurício, comunicação pessoal, 22 de agosto, 2016).

\section{Os Efeitos sobre o Corpo}

É diante das tramas que se estabelecem no contexto de trabalho e foram apresentadas anteriormente que a categoria "Os Efeitos sobre o Corpo" se desenvolve, apontando o sofrimento físico percebido pelos entrevistados. A sobrecarga, o medo, a pressão constante por resultados e a necessidade de manter constantemente os demais trabalhadores engajados nas atividades se traduz em sintomas relacionados ao sofrimento no trabalho. Dentre eles, os entrevistados relataram insônia, dores musculares, problemas digestivos, fadiga, problemas respiratórios e desânimo. Em sua entrevista, Leonora afirma que, no seu caso, as dores são reflexos das características do trabalho. $\mathrm{O}$ fato de exercer sua função de maneira isolada, sem o apoio de outros colegas, tem se tornado um peso para a entrevistada e, em decorrência, efeitos somáticos se multiplicam.

Sim [...]. Eu tenho problema em toda a parte da coluna que eu tô tratando, sinto dor, [...]decorrente dessa somatização de emoções, de frustração [...]isso eu somatizei por causa de levar as coisas nas costas. Sempre sozinha. (Leonora, comunicação pessoal, 08 de agosto, 2016).

Outra entrevistada, apesar de inicialmente afirmar que seus sintomas não são decorrentes da organização do trabalho, por fim relata que eles podem ter se agravado com $\mathrm{o}$ início das suas atividades profissionais.

Então, a insônia é a única somatização que eu percebo, mas eu controlo [...]E então eu sempre tive, só que tem épocas que eu lembro que foi melhor. [...]A partir do momento que eu comecei a trabalhar eu, logo no começo eu tinha bem menos, 
depois foi começando a piorar e tal. (Rafaela, comunicação pessoal, 01 de agosto, 2016).

Outro efeito de sofrimento citado ao longo das entrevistas foi o cansaço. Para exemplificar, traz-se a fala de Antônio, da área de gestão ambiental, que cita o cansaço como sendo algo corriqueiro ao relatar o seu dia a dia de trabalho:

Eu fico exausto, muito cansado. Então, não tem como não dizer que ele não afeta. Esse cansaço é uma junção de tudo. Até porque tem o trânsito e eu acordo todo o dia às cinco e meia da manhã. Aqui dentro, talvez, o que mais gere esse cansaço é a relação com as pessoas. (Antônio, comunicação pessoal, 16 de agosto, 2016).

Percebe-se na fala de alguns entrevistados que existem momentos do trabalho que são mais críticos do que outros para a saúde. No próximo relato, identifica-se que alguns efeitos se agravam em períodos nos quais a tensão ou a pressão aumenta na rotina de trabalho: "As demissões foram em maio e junho, foram os meses mais difíceis e foi quando mais a minha asma atacou" (Leonora, comunicação pessoal, 08 de agosto, 2016).

\section{DISCUSSÃO}

Os dados apresentados anteriormente serão analisados e interpretados à luz dos pressupostos da Psicodinâmica do Trabalho. Diante disso e por meio da colaboração de Silva (2011), entende-se que as características da organização do trabalho podem ser internalizadas pelo sujeito que trabalha. Com isso, o desejo da empresa passa a ser confundido com o desejo do trabalhador, uma característica identificada nos relatos dos executivos entrevistados. Ao refletir sobre a manutenção de normas e regras pautadas na burocracia, na intensificação do ritmo de trabalho e no permanente controle, Merlo e Lapis (2007) afirmam que tais características tornam o trabalho um fardo pesado para o trabalhador, podendo desencadear o desgaste do funcionamento mental e, consequentemente, um desequilíbrio psicoafetivo.

Ao longo das entrevistas, alguns dos executivos relataram que os processos de trabalho tornam o dia cansativo. A repetição de atividades gera sofrimento, o que pode estar relacionado ao estabelecimento de padrões muito rígidos nos modos de produção que, por sua vez, impedem que o trabalhador, mesmo em posição privilegiada dentro da organização, possa expressar a sua subjetividade. Esses dados encontram-se em consonância com os achados de uma pesquisa desenvolvida por Tanure et al. (2014), afirmando que, diante do trabalho, na tentativa de atingir metas e demandas externas, os executivos se submetem à normas burocratizadas, frente às quais não há nada que possam fazer.

Nesse sentido, o grupo entrevistado demonstrou sofrimento frente à monotonia que as rotinas do trabalho lhes impõem e tal fator faz refletir sobre a superficialidade da autonomia outorgada aos profissionais. Percebe-se que essa autonomia é estimulada apenas quando favorece os objetivos organizacionais, fato que pode ser analisado como uma violência perversa das novas relações trabalhistas e demonstra um modo mecanicista da organização ao se relacionar com o indivíduo que trabalha. Pode-se observar junto aos dados coletados que os trabalhadores se sentem desanimados frente à repetição de processos de trabalho, mas que, ao mesmo tempo, há também uma conformidade por parte deles.
Nesse contexto, Clot (2010) afirma que o sofrimento decorrente do mal-estar causado pelos modos de trabalho impostos acaba por transformar o indivíduo em agente passivo frente às circunstâncias. Assim, a passividade frente ao cotidiano de trabalho gera uma crise da representação do indivíduo que tem - ou deveria ter - a liberdade e a autonomia em sua essência. Potencialmente, a partir desse contexto, vê-se o desenvolvimento de patologias como ansiedade e depressão, bem como a paralisia da capacidade de agir e de empreender (Bendassolli, 2011).

Entende-se que os executivos deixam de lado as próprias conviç̧ões e passam a adotar a ideologia e a cultura impostas pelo trabalho. Dessa forma, tende-se a supor que a prática de reflexão sobre diferentes formas de trabalhar se esvaziam com o tempo, reduzindo, assim, a possibilidade de modificações das práticas existentes, tornando o sujeito um membro apático e com potencial risco de adoecimento.

Dejours (1980/2010) afirma que o trabalho se torna nocivo ao aparelho psíquico quando ele se opõe à livre atividade. Do contrário, quando a organização não permite a livre atividade, quando os espaços para a criação são escassos ou inexistentes, a energia psíquica se acumula, gerando sofrimento e desprazer, além de fazer do trabalho uma atividade fatigante (Dejours, 2010). Esse elemento se torna ainda mais relevante quando, como no caso desses executivos, a liberdade para atuação é oferecida como algo possível, mas que na prática não se concretiza ou acontece em partes; partes essas já previstas e manipuladas pela organização de trabalho. Nessa dinâmica perversa de relações com o trabalho, o executivo que foi contratado para exercer a autonomia, não o faz. Ao não o realizar, fica à mercê das dúvidas quanto à própria identidade e capacidade e os resultados disso ultrapassam as delimitações do espaço de trabalho, afetando então o corpo e a mente do executivo, bem como as suas relações com os demais contextos sociais.

Outro fator a ser pensado nessa discussão e que foi referido pelos entrevistados é o sofrimento frente às normas de qualidade. Devido às exigências de qualidade, as indústrias buscam padronizar o comportamento e as ações 
de seus colaboradores. Essa tendência leva ao embotamento emocional e ao sofrimento. Percebeu-se que os executivos são responsáveis pela apresentação dos resultados exigidos pela organização. Dessa forma, tornam-se alvos fáceis das vivências de sofrimento frente às rotinas de cobranças.

A cobrança quanto à qualidade do produto é uma preocupação constante dos executivos em geral e, de acordo com um dos entrevistados, qualquer erro pode tomar proporções muito violentas, aumentando assim a carga de tensão que acompanha as rotinas de trabalho. Os trabalhadores passam a assumir como próprio o "desejo de perfeição" que na verdade é da organização e, frente a isso, a cometer um ato que prejudique o alcance dessa perfeição. Tal ato tem consequência grave para a identidade do sujeito, já que é o próprio trabalhador que fica com a imagem comprometida. Acaba-se, com isso, aceitando ou até mesmo banalizando injustiças sociais, como as exigências descabidas e opressoras de perfeição a qualquer preço (Moraes, 2008).

Ao analisar os dados coletados, bem como as características da organização do trabalho dos executivos, percebe-se que o maior fator de sofrimento entre os entrevistados, atualmente, está relacionado aos desligamentos dos trabalhadores nas indústrias do setor alimentício. A crise financeira e a recessão econômica que o país vem enfrentando nos últimos anos refletem, principalmente, nos setores industriais.

Percebeu-se ao longo da coleta de dados que o contexto social e econômico que se estabelece forçou a reorganização das formas de trabalhar, tanto para os executivos como para as suas equipes de trabalho. De acordo com Merlo e Lapis (2007), diante da ameaça do desemprego, os trabalhadores passam a vivenciar experiências de medo e de insegurança dentro do contexto de trabalho, reforçando a quebra da cooperação e da solidariedade no coletivo de trabalho.

Ao longo da reflexão sobre esse tema, se torna evidente que os efeitos das demissões são sentidos tanto pelo corpo como pelo funcionamento e pela dinâmica psíquica dos indivíduos, traduzindo-se em sintomas físicos e psíquicos. Frente às colocações dos entrevistados, vale ressaltar as considerações de Antunes (2010) quanto ao desemprego, considerando que esta é a pior face da precarização do trabalho. Pode-se compreender, a partir desses relatos, que o sofrimento atinge também quem se mantém empregado. Esses trabalhadores, além de vivenciarem relações precárias de trabalho, também são forçados a lidarem com a ausência dos colegas. Outro elemento importante é que, de alguma forma, o executivo acaba tomando para si o sentimento de responsabilidade pelos desligamentos. Pode-se pensar, a partir disso, em uma organização do trabalho que impõe aos seus gestores um modo de trabalhar pautado na individualidade e na responsabilização, fazendo com que os executivos assumam como suas as características da própria organização do trabalho.

O fator da individualização das responsabilidades que a organização do trabalho impõe a cada executivo do setor de alimentos, além de, segundo Dejours (1989/2010), gerar sofrimento e impedir o desenvolvimento de conhecimento, reforça o sentimento de insegurança. De acordo com Dejours (2005), o medo frente ao possível desligamento gera atitudes de obediência e até de submissão, além de quebrar a reciprocidade, reforçando a premissa do "cada um por si”. Nesse contexto, a falta de crítica relacionada a alguns procedimentos que podem denegrir tanto o ambiente como as relações de trabalho faz com que se anule a mobilização individual ou coletiva, em prol da possibilidade de mudança e busca por um ambiente de trabalho diferente.

Frente à rigidez da organização do trabalho, da inflexibilidade das normas de qualidade, da atual situação econômica do país, do elevado índice de desemprego e do medo que os trabalhadores vivenciam diante da possibilidade do seu próprio desligamento, algumas estratégias defensivas são identificadas. Entre elas, as mais frequentes são a racionalização, a banalização e a submissão. Ressalta-se, no entanto, que o conjunto de estratégias identificadas, apesar de serem fundamentais para a manutenção da saúde mental momentânea, podem ser analisadas como os primeiros passos a caminho da servidão voluntária, termo cunhado inicialmente por La Boétie (2003) ao se referir à população que abre mão de sua própria liberdade em prol da servidão ao soberano e à proteção que este pode lhe oferecer.

Como apresentado durante a exposição das características da organização do trabalho que regem a atuação dos executivos, de maneira geral, todos eles despendem um tempo que seria próprio para os cuidados com a vida pessoal, familiar e social para atividades de trabalho. Esse elemento corrobora com os achados de Mota et al. (2008), ao identificarem como majoritários no Brasil os perfis de executivos que não conseguem se desligar do trabalho, postergando ou mesmo rejeitando os momentos de lazer e com a família, sendo estes mais suscetíveis ao estresse.

Nesse contexto, torna-se relevante a reflexão acerca dos prejuízos que a naturalização dessa sobrecarga pode gerar ao corpo. Pode-se considerar a imposição de dedicação plena como uma violência, tanto para o corpo como para a mente do trabalhador. Sobre isso, Dejours e Abdoucheli (1982) afirmam que o limite que a organização do trabalho impõe ao desejo pode ter respostas trágicas físicas e mentais para o sujeito que trabalha. Fato este que é negado, em diversos momentos, pelo trabalhador que toma o seu sintoma como algo crônico e, por sua vez, sem ligação ou nexo causal com as atividades de trabalho, retardando, assim, uma possível solução.

Todos os sintomas que tomam a mente e o corpo dos trabalhadores são agravados pela falta do coletivo de trabalho. Bendassolli e Soboll (2014), ao se pronunciarem sobre as clínicas do trabalho, relatam que um sinal importante da vulnerabilidade à qual o trabalhador é exposto diariamente é o processo de individualização e a destruição dos coletivos de trabalho. Nesse sentido, percebeu-se entre os entrevistados que a falta de interação entre colegas do mesmo nível hierárquico tem se tornado um fator de sofrimento. A ausência desse coletivo de trabalho, além de proporcionar que o sofrimento ganhe forças ao expor o 
executivo individualmente às provações do dia de trabalho, ainda impede a sua ressignificação e interfere no processo de mudança de elementos que poderiam transformar as expressões de sofrimento e seus efeitos sobre o corpo.

Diante disso, ressalta-se a relevância que os próprios executivos impõem às relações de trabalho, um fator que torna ainda mais agravante o isolamento ao qual estão expostos esses trabalhadores ao longo de suas rotinas de trabalho. Por mais que consideremos as relações como parte integrante da organização do trabalho, sabe-se que, além de compô-la, as relações são também um efeito. De maneira geral, ao serem questionados sobre as influências que os demais trabalhadores sofrem a partir das relações estabelecidas com os próprios executivos, todos afirmaram a sua existência, fator que mobiliza sentimentos variados nas equipes de trabalho.

O cargo em que atuam esses profissionais também é caracterizado pela cobrança frente à gestão de pessoas. As relações que se estabelecem entre executivo e equipe são consideradas essenciais para a manutenção do sentido de trabalho, do engajamento e da cooperação entre os membros da equipe. Entende-se, nesse sentido, que a organização do trabalho em que se inserem executivos impõe que exerçam um papel de mediação entre o que deseja a indústria e as necessidades dos sujeitos que trabalham. Essa mediação se dá, muitas vezes, ao custo da servidão desses profissionais. Nesse sentido, o trabalhador que tem a função de atingir os objetivos organizacionais, se vê frente à necessidade de se eximir dos próprios sentimentos em relação às suas atividades. Dentro desse contexto, além de não demonstrar seus sentimentos, necessitam, ainda, evitar os sentimentos negativos entre a sua equipe de trabalho.

Em uma reprodução velada da realidade imposta pelo modelo taylorista, as organizações do trabalho nas indústrias de alimentos impõem a premissa de manter a "melhor pessoa" realizando a tarefa da "melhor maneira", sem espaço para questionar-se ou questionar a organização. $\mathrm{O}$ grupo de executivos pesquisados relatou que a motivação, 0 desempenho e o humor da equipe são fatores fundamentais para o sucesso do trabalho. Assim, percebe-se uma mobilização constante desses profissionais para que a sua equipe se mantenha em harmonia, independente dos acontecimentos diários, reduzindo, assim, os espaços de interação coletiva, de reflexão e de possibilidades para dúvidas e questionamentos.

\section{CONSIDERAÇÕES FINAIS}

Ao se analisar especificamente a função dos executivos do setor, ressalta-se características importantes do cargo como o gerenciamento de processos e colaboradores, a responsabilidade pelo cumprimento e pelo alcance das metas. Além disso, destaca-se o regime de trabalho diferenciado, pautado especialmente em um modo de trabalhar que exige do profissional uma dedicação exclusiva, demandando longas jornadas de trabalho.

A partir da análise dos dados, ressalta-se que o medo do desligamento surge como um dos maiores fatores de sofrimento entre os executivos. No entanto, além disso, aponta-se outros aspectos, como a necessidade de se responsabilizarem individualmente pelos resultados da empresa, a sobrecarga de trabalho, o excesso de cobrança, a rigidez frente aos processos de qualidade e a falta de um coletivo entre os profissionais que estão em um mesmo nível hierárquico.

Outro elemento importante destacado por essa pesquisa e que, por sua vez, agrava os elementos citados anteriormente, é a necessidade que esses profissionais enfrentam de se calarem e de negarem a própria opinião, abdicando de seus sentimentos e anulando a sua subjetividade em relação aos processos de trabalho, em prol dos objetivos da empresa. Dessa forma, além de enfrentarem sozinhos as mazelas do trabalho, são impossibilitados de expressar seus sentimentos. Nesse sentido, identificou-se efeitos possivelmente atrelados a essas vivências, como dores nas costas, cansaço, estresse e agravamento de sintomas crônicos, como insônia e gastrite. Ao longo da coleta, percebeu-se que a organização do trabalho é negligente com cuidados à saúde mental dos trabalhadores em geral e que suas atividades são pautadas, principalmente, sobre o acúmulo de capital, mesmo quando isso significa pôr em risco a saúde de seus colaboradores. Essa organização de trabalho promove modos mecanicistas de ser, disseminando a precarização das relações sociais e agravando os riscos à integridade física e psíquica dos trabalhadores. Atenta-se para a naturalização das condições precárias do trabalho industrial em prol da manutenção dos cargos de gestão. Essa naturalização coloca os executivos em uma posição passiva frente ao sofrimento, fazendo com que tais características se repitam e se instituem como normas únicas, tornando-se padrões para a subjetivação dos trabalhadores.

Dentre as limitações desta investigação, ressalta-se a pequena abrangência geográfica alcançada, o recorte histórico e a escassez de achados literários a respeito do mesmo tema, evidenciando a necessidade de continuação das pesquisas. Apesar das limitações, percebeu-se a relevância dessa pesquisa frente à problematização, prevenção e promoção da saúde mental dos executivos da indústria tão pouco evidenciados, mas que, em contrapartida, exercem grande influência sobre os demais trabalhadores.

As análises presentes neste documento corroboram com outros achados relacionados às características organizacionais vinculadas ao desencadeamento de estresse em profissionais que ocupam cargos hierarquicamente mais elevados (Mota et al., 2008; Tanure et al., 2014). No entanto, ressalta-se o caráter problematizador desta pesquisa na tentativa de identificar formas mais veladas de sofrimento, apontando para as dinâmicas e relações que possam estar causando ou agravando tais vivências. 
Assim, cabe ressaltar a importância da disseminação das teorias acerca da influência que a organização do trabalho exerce sobre a saúde mental dos trabalhadores. A aproximação da psicologia com esses contextos pode dar voz à subjetividade de quem trabalha, oportunizando a reflexão sobre tais temas, e possibilitando a ressignificação do sofrimento e a mobilização a caminho de novas e mais saudáveis formas de organização do trabalho.

\section{REFERÊNCIAS}

Antunes, R. (2010). Os Sentidos do Trabalho: Ensaio sobre a Afirmação e a Negação do Trabalho. Boitempo.

Antunes, R., \& Alves, G. (2004). As Mutações do Mundo do Trabalho na Era da Mundialização do Capital. Educação e Sociedade, 25(87), 335-351. https://doi.org/10.1590/S010173302004000200003

Bendassolli, P. (2011). Mal-Estar no Trabalho: Do Sofrimento ao Poder de Agir.Mal-Estar e Subjetividade, 1, 63-98.

Bendassolli, P. F., \& Soboll, L. I. P. (2014). Métodos de Pesquisa e Intervenção em Psicologia do Trabalho: Clínicas do Trabalho, 1a ed. Atlas.

Bertê, A. M. A., Lemos, B. O., Testa, G., Zanella, M. A. R., \& Oliveira, S. B. (2016). Perfil Socioeconômico - Corede Vale do Caí. Boletim geográfico do Rio Grande do Sul, 26, 869-908.

Biernacki, P., \& Waldorf, D. (1981). Snowball Sampling: Problems and Techniques of Chain Referral Sampling. Sociological Methods \& Research, 10, 141-163.https://doi. org/10.1177/004912418101000205

Cardoso, F. L. A. (2012). A "Via Crucis" para a Legalização da Agroindústria Alimentar: Impacto Social da Legislação Sanitária na Agricultura Familiar. [Dissertação de Mestrado, Universidade de Brasília] http://repositorio.unb.br/ bitstream/10482/10418/1/2012 FabioLucioAlmeidaCardoso. pdf

Casttells, M. (1999). A Sociedade em Rede (A Era da Informação: Economia, Sociedade e Cultura). Paz e Terra.

Clot, Y. (2010) Trabalho e Poder de Agir. Fabrefactum.

Couto, H. A. (1987). Temas de Saúde Ocupacional. ERGO.

Couto, H. A. (1987). Stress entre Executivos: Os 10 Agentes Estressantes Mais Freqüentes e os 13 Fatores de Maior Potencial Agressivo. Anais do Congresso da Associação Nacional de Medicina do Trabalho, 5, 747-57.

Dejours, C. (1980/2010). A Carga Psíquica do Trabalho. Societé Française de Psychologie - Psychologie du Travail - Equilibre ou fatigue par le travail? Paris: lenterprise Moderne d'Édition. Em C. Dejours, E. Abdoucheli, \& C. Jayet. (Eds.), Psicodinâmica do trabalho: Contribuições da Escola Dejouriana à Análise da Relação Prazer, Sofrimento e Trabalho, 21-32. Atlas.

Dejours, C. (1989/2010). Trabalho e Saúde Mental: Da Pesquisa à Ação. Mouvement Ouvrier et Santé: Une Comparaison Internationale. Em C. Dejours, E. Abdoucheli, \& C. Jayet (Eds.), Psicodinâmica do Trabalho: Contribuições da Escola Dejouriana à Análise da Relação Prazer, Sofrimento e Trabalho, 45-65. Atlas.

Dejours, C. (2004). Subjetividade, Trabalho e Ação. Revista Produção, 14(3), 27-34. http://dx.doi.org/10.1590/S010365132004000300004

Dejours, C. (2005). A Banalização da Injustiça Social, 7a ed. FGV.

Dejours, C., \& Abdoucheli, E. (1982). Desejo ou Motivação? A Interrogação Psicanalítica sobre o Trabalho. Em M. Moulin (Org.), Quelles Motivations au Travail? Enterprise Moderne d'Edition.

Dejours, C., Abdoucheli, E., \& Jayet, C. (2010). Psicodinâmica do Trabalho: Contribuições da Escola Dejouriana à Análise da Relação Prazer, Sofrimento e Trabalho. Atlas.
La Boétie, E. (2003). Discurso sobre a Servidão Voluntária, 2a ed. (J. Castella Jr. \& A. Cretella, trad.). Revista dos Tribunais Ltda.

Lancman, S., \& Ghirardi, M. I. G. (2002). Pensando Novas Práticas em Terapia Ocupacional, Saúde e Trabalho. Revista de Terapia Ocupacional da USP, 13(2), 44-85.

Laranjeira, S. M. G. (2000). As Transformações do Trabalho num Mundo Globalizado. Sociologias, 4, 14-19.https://dx.doi. org/10.1590/S1517-45222000000200002

Laville, C., \& Dionne, J. (1999). A Construção do Saber: Manual de Metodologia da Pesquisa em Ciências Humanas. Artmed.

Maffia, L. N., \& Pereira, L. Z. (2013). Estresse Ocupacional: Estudo com Gestores que Atuam nas Secretarias de Governo do Estado de Minas Gerais. XXXVII encontro da ANPAD, Rio de Janeiro.

Martins, S. R., \& Mendes, A. M. (2012). Espaço coletivo de discussão: A clínica psicodinâmica do trabalho como ação de resistência. Revista Psicologia Organizações e Trabalho,12(2), 171-183.

Mendes, A. M. (1995). Aspectos Psicodinâmicos da Relação Homem-Trabalho: As Contribuições de C. Dejours. Psicologia: Ciência e Profissão,15(1-3), 34-38.https://dx.doi.org/10.1590/ S1414-98931995000100009

Mendes, A. M., \& Facas, E. P. (2010). Transgressão do Trabalho Prescrito como Estratégia para Transformar o Sofrimento: Estudo da Inteligência Prática. Em A. M. Mendes, A. R. C. Merlo, C. F. Morrone, \& E. P. Facas (Orgs.), Psicodinâmica e Clínica do Trabalho: Temas, Interfaces e Casos Brasileiros, 77-92. Juruá.

Merlo, Á. R. C., \& Lapis, N. L. (2007). A Saúde e os Processos de Trabalho no Capitalismo: Reflexões na Interface da Psicodinâmica do Trabalho e da Sociologia do Trabalho. Psicologia \& Sociedade,19(1), 61-68.https://dx.doi. org/10.1590/S0102-71822007000100009

Moraes, R. D. (2008). Prazer-Sofrimento e Saúde no Trabalho com Automação: Estudo com Operadores em Empresas Japonesas no Pólo Industrial de Manaus. [Tese de Doutorado, Universidade Federal do Pará]. http://repositorio.ufpa.br/jspui/ handle/2011/3453

Mota, C. M., Tanure, B., \& Carvalho Neto, A. (2008). Estresse e Sofrimento no Trabalho dos Executivos. Psicologia em Revista,14(1), 107-130.

Oltramari, A. P., Grisci, C. L. I., \& Weber, L. (2011). Carreira e Relações Familiares: Dilemas de Executivos Bancários. Revista Mal-Estar e Subjetividade, 11(1), 101-133.

Sarriera, J. C., \& Silva, M. A. (2003). O Executivo Pós-Moderno: Transformações no Trabalho e Subjetividade. Psicologia Organizações e Trabalho,3(2), 35-62.

Sato, L., \& Lacaz, F. A. C. (2000). Condições de Trabalho e Saúde dos Trabalhadores (as) do Ramo da Alimentação. INST - CUT.

Silva, E. S. (2011). Trabalho e Desgaste Mental: O Direito de Ser Dono de Si Mesmo. Cortez.

Tanure, B., Carvalho Neto, A., Santos, C. M. M., \& Patrus, R. (2014). Estresse, Doença do Tempo: Um Estudo sobre o Uso do Tempo pelos Executivos Brasileiros. Estudos e Pesquisas em Psicologia, 14(1), 65-88.

Vasconcelos, A., \& Faria, J. H. (2008). Saúde Mental no Trabalho: Contradições e Limites. Psicologia \& Sociedade,20(3), 453464. https://dx.doi.org/10.1590/S0102-71822008000300016 